ta di Filosofia Neo-Scolastica, Lxxuvi, Pp. 747-749.

Mortera, Saúl Leví (1988): Tratado da Verdade da Lei de Moisés, Universidad de Coimbra.

SPINozA, Baruch de (1924): Spinoza Opera, Carl Gebhardt, Heidelherg, Carl Winters (ed. 1972). Las traducciones del $T T P$ y de la Correspondencia utilizadas aquí son de Atilano Domínguez, y han sido publicadas por Alianza Editorial (núms. 1.185 y 1.305 , respectivamente). Stemmetz, David C. (1988): "Calvin and the absolute power of God\%, Journal of
Medieval and Renaissance. Studies, 18, pp. 65-79.

TEMPLE, William (1692): Remarques sur l'Estat des Provinces Unies faites en l'an 1672, La Haye, Chez Jean \& Daniel Stenker.

TRACY, D. (1985): «With and without the Counter-Reformation: The Catholic Church in the Spanish Netherlands and the Dutch Republic, 1580-1650\%, Catholic Historical Review, 71, pp. 547-575.

VERBEEK, Theo (1990): «Le Contexte Néerlandais de la Politique Cartésienne», Archives de Philosophie, 53, pp. $357-370$.

\title{
De R. Rorty a J. Dewey: notas sobre filosofía, democracia y comunidad
}

\author{
RAMÓN DEL CASTILLO SANTOS \\ Dpto. de Filosofja \\ UNED, Madrid
}

Me propongo discutir en estc trabajo el significado que ha adquirido la figura de John Dewey en la obra de Richard Rorty. Intentaré mostrar brevemente que las relaciones que Rorty ha ido estableciendo entre su neopragmatismo y el que Dewey desarrolló desde la primera década del siglo no están exentas de contradicciones, y que la convivencia de argumentos deweyanos y rortyanos sobre la naturaleza de la filosofía y la legitimación de la demo. cracia es mucho más compleja y polemica que lo que cl propio Rorty ha dado a entender. Aunque Richard Bernstein y Thomas McCarthy han insinuado en recientes ocasiones ${ }^{1}$ las dificultades que encierra el uso que hace Rorty de argumentos de Dewey, lo cierto es que la dis- cusión que en 1985 tuvieron R. Sleeper, A. Edel y el propio Rorty sobre Consequences of Pragmatism ${ }^{2}, \operatorname{los}$ numerosos y cada vez más detallados trabajos de especialistas sobre Dewey ${ }^{3}$, la crítica de Cornell West a Rorty ${ }^{4}$ apoyada, justamente, en las implicaciones del pragmatismo de Dewey para rehabilitar el modelo del intelectual radical o incluso los últimos trabajos que Hilary Putnam ha dedicado a Dewey y al pragmatismo ${ }^{5}$ han contribuido a hacer muy evidentes no sólo diferencias de énfasis, sino autênticas contradicciones entre el modelo de filosofía práctica y de democracia radical de Dewey y la irónica visión de Rorty frente a las relaciones entre filosofía y política en las democracias liberales. 
«moral» 7 ; 2) que «su tarea principal es la de aclarar, liberar y extender los bienes

A pesar de to que Rorty dijo desdo Phi. losophy and the Mirror of Nature, no creo que lo relevante del vinculo entre su pragmatismo y el de Dewey sea una común aspiración a superar la noción contemporánea de una tcoría del conocimiento. Es cierto que a Dewey le interesaba superar esa idea de la filosofía y que criticó aquellas tradiciones filosóficas que intentaban justificar la racionalidad de otras prácticas como la cientifica y la política describiendo condiciones trascendentales del conocimiento y principios generales que determinan la práctica. Esta defensa deweyana de la autonomía de la racionalidad práctica se expresa muy bien en «Experience and Philosophical Method", de Expertence and Nature, cuando dice que «los filósofos han negado que la experiencia común sea capaz de desarrollar desde si misma métodos que aseguren su propia dirección y que creen patrones inherentes de juicio y valor... Al gasto de tiempo y energía, a la perdida de ilusión por una vida que atienda a todo producto de la experiencia concreta, debe añadirse el trảgico error de descubrir el valor que la investigación inteligente podría revelar y madurar entre las cusas de la experiencia ordinaria... Probablemente el filosofo trascendental ha hecho más que el proceso sensualista o el materialista para oscurecer las potencialidades que tiene la experiencia ordinaria para fomentar el bien y el autocontrol» ${ }^{\mathrm{t}}$. No hay duda de que Dewey conectó el giro pragmático de la filosofia, la crítica a las aspiraciones fundamentadoras de la teoría del conocimiento y de la política, con esta concepción de la autonomía de las prácticas. Por eso, afirmó sin ambigüedades: 1) que la filosofia misma debería considerarse como una actividad más entre otras que contiene consideraciones valorativas indispensables para su existencia como tal, y cuya función es «práctica» 0 que se producen en las funciones de la experiencia generadas naturalmente» 8 3) que "no tiene capacidad para crear un mundo "real" de novo, ni para ahondar en los secretos del Ser ocultos para el sentido común y la ciencia " ${ }^{9}$ y 4 ) que no «tiene un depósito de información o un cucrpo de conocimiento peculiarmente propio... Su tarca es accptar y utilizar, para algún fín, el conocimiento disponible de su momento y su entorno. $\mathrm{Y}$ ese fin es la crítica de creencias, instituciones, costumbres y políticas en relación con su efecto sobre el bien. Esto no significa su efecto sobre el bien, como algo que se formula y se determina dentro de la filosofía. Puesto que la filosofía no tiene una fuente privada de conocimiento o de métodos para alcanzar la verdad, tampoco tiene un acceso privado al bien. $Y$ en la medida en que acepta el conocimiento de hechos y los principios que proporcionan los expertos en ciencia y otras investigaciones, acepta los bienes que están difundidos en la experiencia humanas ${ }^{10}$. No es extraño, por tanto, que si la filosofía dejase de ocuparse del problema del conocimiento y de la acción en los términos tradicionales (incluidos el positivismo lógico y el neokantismo, según Dewey), su función debería ser participar en la interacción entre creencias de distinto tipo: científicas y del sentido común, artísticas y políticas.

Rorty nunca ha ocultado su admiración por esta imagen de la racionalidad que acabo de esbozar. En Philosophy and the Mirror of Nature, por ejemplo, asociaba incluso las teorias contemporáneas sobre la naturaleza del conocimiento y del lenguaje con el impulso a ver las prácticas sociales de producción y justificación de conocimiento y de significado como algo más que tales prácticas. Pero, para ćl, a diferencia de Dewey, esa crítica a un amétodo» filosófico que descubra caracterís- 
ticas generales de la racionalidad y autoridad del conocimiento y del lenguaje, ha significado una negación radical de cualquier forma de filosofía con aspiraciones reconstructivas que se pudiera desarrollar en el futuro. Por decirlo de otra forma: Rorty no cree que la filosofía pueda interactuar con esas prácticas sin poblar nuestra cultura de nociones que obstaculicen gravemente su libre desarrollo. Para Rorty, esa reverencia deweyana por la suficiencia de las prácticas forma parte de un argumento a favor de una separación radical entre filosofía y justificación de fines sociales $\mathrm{o}$, más exactamemte, entre filosofia $y$ política ${ }^{11}$. Como ha dicho: «No debemos suponer que nuestra tarea como profesores de filosofía es la de ser la vanguardia de los movimientos políticos... Deberíamos considerar la política como una disciplina experimental, no como una disciplina teóricas ${ }^{12}$.

Obviamente, la oposición que Rorty señala aquí entre la política como experimento y como teoría busca su apoyo en Dewey; pero, cnunciada asi (como ha hecho en Contingency, irony and solidarity y en otros ensayos de Philosophical papers I), esa oposición simplifica la convicción deweyana de que a la filosofía aún le quedaba la tarea de interactuar con acciones de las instituciones y de movimicntos sociales sin tener que conccbirse necesariamente como su vanguardia. Dicho en otras palabras: criticar el uso filosófico de nociones y la búsqueda de justificaciones más generales que las que ofrecen los participantes en las prácticas cientificas, politicas o jurídicas nunca significó para Dcwey que la filosofía tuviera que reprimir su intervención pública y convertirse, como quiere Rorty, en parte de nuestras fantasías privadas, para evitar sus consecuencias no deseadas.

Es importante insistir en que el hecho de que las prácticas establecidas determinen desde dentro los criterios de compe- tencia y ejemplifiquen ellas mismas, con el uso, su modo de aplicación, implicaba para Dewey precisamente lo contrario que para Rorty: si la filosofía reconocía que estas prácticas pueden mantener unida a la cultura sin una justificación trascendental, entonces la filosofia, diria Dewey, tienc aún una mayor obligación de buscar formas para convertirse en una práctica con la aspiración de intervenir públicamente en la comunicación de unas prácticas con otras. Esto no quiere decir, para Dewey, que la filosofía pueda descubrir un léxico común a todas las prácticas, sino que se esforzaría en imaginar y aplicar medios de muy diversos tipos con los que cada práctica pudiera expresar su carácter diferencial. Dewey partía de la convicción de que las distintas formas de vida de una cultura democrática sólo adquieren su verdadero perfil cuando se ven necesitadas de actuar entre sî en una serie de contextos distintos.

La reflexión sobre las variedades de acción social que Dewey identificó con la filosofía del futuro no tiene que tratar de fundamentar las prácticas (por ejemplo, las condiciones de un intercambio de información lo más libre posible y la creación revolucionaria de paradigmas en las ciencias, o la solución normal de problemas en los ámbitos jurídicos y políticos ordinarios) en algo más amplio como una teotía general del progreso del conocimiento o de la comunicación o de la justicia. Como él mismo dicc, las teorías sociales tradicionales que han estado tan conectadas con la filosofia han cometido un mismo error: «el compromiso con la lógica de las nociones generales de las que se deducen situaciones específicas (...). La discusión tiene lugar en términos de el Estado, $e l$ individuo, la naturaleza de las instituciones como tales, la sociedad en general». Sería imprescindible desplazar ese modelo e intentar, directamente, «arrojar luz sobre este o aquel grupo de individuos, este $o$ aquel ser humano concreto, esta o aquella 
institución o relación social especifica» ${ }^{13}$. Esto significaba que, para él, la necesidad de aclarar las prácticas sin un modelo fundamentador apremiaba aún más la búsqueda de nuevas formas en las que comprometer a los intelectuales en la política social y cultural para así contribuir a mostrar los vínculos y las diferencias entre esas prácticas y para plantcar una serie de problemas apremiantes para una filosofía pragmatizada. Por ejemplo: con qué medios se deben poner en conexión en cada situación unas prácticas con otras y qué tienen que decir sobre eso el Estado administrativo, los expertos en ciencia social y los grupos sociales implicados, o cómo apartar a una ciencia social empírica y pragmatizada del simple servicio al Estado como una ingeniería social que acepta los fines de aquél ${ }^{14}$.

La imagen de la inteligencia como un instrumento sirvió a Dewey, antes de nada, para enfatizar la relación interna que guardan los medios y los fines, o sea, la imposibilidad de separar nuestra comprensión de un fin de las acciones habituales que han estado constitutivamente unidas a la implantación de un léxico sobre ese fin: «Los bienes y los fines morales existen únicamente cuando es preciso hacer algo. El hecho mismo de que haya que hacer algo es una prueba de que en la situación existente hay deficiencias y males... es preciso descubrir, proyectar y alcanzar el bien de esta situación sobre la base del defecto y de la dificultad exacta cuya rectificación se impone. Es imposible inyectarlo de una manera inteligente desde fuera de la situacións '5; «no podemos buscar ni alcanzar la salud, la riqueza, el saber, la justicia o la bondad en términos generales. El obrar es siempre específico, concreto, individualizado, único. Por consiguiente, también los juicios que se refieren a los actos que tenemos que realizar habrán de ser concretos. Decir que un hombre busca la salud o la justicia es lo mismo que decir que busca el vivir saludablemente o justamente ${ }^{16}$. Por tanto, aunque llamemos bienes a cosas como la salud o la justicia, con eso sólo sugerimos posibles rasgos de la experiencia que es preciso estudiar en cada caso particular $y$, en consecuencia, cada uno de esos conceptos - «salud», «justicia», «riqueza», «libertad, «derecho», etc.- son «instrumentos de penetración de un problema; su valor cstá en provocar una respuesta individualizada dentro de la situación individual» ${ }^{17}$. Por ejemplo: los médicos no tienen una idea de la salud como un fin-en-sí-mismo y absoluto, a través del cual determinar lo que hay que hacer. Por el contrario, «crean su idea general de la salud como un fin y un buen valor para sus pacientes apoyándose en que sus técnicas de examen han mostrado cuáles son los problemas que sufre un paciente y cuáles los medios por los que se superan" ${ }^{18}$. También en el ámbito de los términos legales Dewey comentó: «Incluso cuando el significado de ciertas palabras legales está determinado por un tribunal, no es el acuerdo de los jueces lo que es finalmente decisivo. Ese acuerdo no pone final al asunto. Más bien tiene lugar como un medio para determinar futuros acuerdos sobre conductas similares, y es ese comportamiento subsiguiente lo que finalmente establece el significado efcctivo de las palabras en cuestión» ${ }^{19}$.

Dewcy pensó que la filosolia tradicional había justificado tácitamente su cxistencia en la separación antinatural de medios extrinsecos, puramente instrumentales, y fines en sí mismos, para así desarrollarse hipnotizada por la idea de que su tarea consistía en descubrir alguna finalidad o algún fin último. Esta idea, aplicada al campo social y político, le sirvió para sostener que en política, como en tantas otras actividades humanas, el entendimiento lógico y conceptual de una idea, un fin, o un valor no tiene por qué preceder a una expresión institucional de la misma ni 
a su articulación en un léxico coherente desde un punto de vista lógico ${ }^{20}$. De hecho, la tesis deweyana de la continuidad entre medios y fines aplicada al campo de los valores políticos viene a significar que ideas como la de libertad y justicia sólo pueden llegar a hacerse claras a través de las mismas acciones que, se supone, crean libertad y justicia, o que el proceso práctico y cmpírico de deliberación y argumentación conticne las condiciones de realización de cualquier programa. La creación de justicia y libertad más la comprensión de esas ideas son, para Dewey, parte de un mismo e indivisible proceso cuya separación asociaba con un estancamiento del progreso moral en la democracia. Ahora bien, Dewey no dedujo de esta idea la tesis de que la filosolia no podria encontrar otra forma beneficiosa de seguir interactuando con el resto de las prácticas sociales. Todo lo contrario, como hemos visto más arriba, le empujo a pensar que su función podía ser la de presenvar la coherencia interna que guardan los valores sociales con las acciones básicas que, sobre la marcha, se han tenido que realizar, o se está intentando llevar a cabo, para poder comprender los fines que dicen perseguirse y para, en ültima instancia, conseguir que esos fines produzcan buenos resultados.

Frente a esta búsqueda de formas de interacción de la filosofia con otras prácticas, las esperanzas que Rorty tiene en el futuro de la filosofía son bastante distintas. En primer lugar, Rorty admira esta idea de que los léxicos deben tomarse más como herramientas alternativas que como piezas de un rompecabezas. Esto último equivaldría a suponer que pueden ser prescindibles o reducibles a otros léxicos, o bien que pucdan ser reunidos con otros léxicos en uno unificado. $Y$ tiene razón al indicar que, si los tomamos por herramientas, veremos qué poco sentido tiene contestar a preguntas como aiqué lugar ocupan los valores en un mundo de hechos? ${ }^{21}$. Si entendemos los léxicos como hizo Dewey, entenderiamos que en la mayoría de los casos los fines y propósitos de un léxico no se pueden precisar antes de llevarlos adelante de una forma práctica, antes de producir ciertos efectos en otros hablantes y en distintos contextos y que, por tanto, cualquier evaluación sig. nificativa de fines siempre debe incluir una evaluación de sus acciones concretas. Rorty sabe que Dewey extrajo de esto un corolario muy importante para su concepción de la democracia, a saber: sólo cuando la discusión sobre un fin en general se sus." tituye por la discusión sobrc las acciones concretas (medios disponibles o alcanzables con alguna modificación) para alcanzar ese fin se pueden experimentar nuevos resultados que fomenten la posibilidad de los cambios que asociamos con una forma democrática de desarrollo social ${ }^{22}$. Los fines democráticos pueden definirse, cn términos generales, como un ideal; pero como un punto de vista desde el que observar las condiciones existentes y juzgar la dirección que debería adoptar el cambio, ese ideal «no puede - dice Dewey- ser demasiado inclusivo. Pero el problema de producir cambio requiere infinita atención a los medios, y éstos sólo pueden detcrminarse con un análisis preciso de las condiciones de cada problema a medida que se presenta» ${ }^{23}$.

Este corolario de su modelo general de acción pertenece al corazón de la teoría deweyana de la democracia, que no consiste en un conjunto de principios ${ }^{24}$. $\mathrm{La}$ democracia no se fundamenta ni siquicra en un conjunto de instituciones o procedimientos formales como el sufragio, sino que es «la única forma dc vivir que, comparada con otras formas de vida, cree con plena confianza en el proceso de la expericncia como fin y como medio ${ }^{25}$. Se trata, pues, de la única forma de vida que asumiría la continuidad entre medios y fines y que intentaría construir relaciones 
sociales entre sus miembros adoptando una actitud empinica hacia los fines inclusivos. Si la tarea de desarrollo y enriquecimicnto de la experiencia «no tiene fin hasta que la experiencia misma llega a un fin, 26 , si «la dependencia de los fines respecto a los medios es de tal naturaleza que el único resultado definitivo es el obtenido hoy, mañana, pasado mañana, al día siguiente, en la sucesión de años y generaciones», entonces "el método democrático resulta tan fundamentalmente simple y $\tan$ inmensamente difícil como puede serlo la crcaciốn enérgica, consecuente $\mathrm{e}$ incesante, de un camino nuevo sobre el cual podamos marchar juntos» ${ }^{27}$. O sea, la forma democrática de asegurar la libertad y la justicia no sólo consiste en legitimar formas de proceder, sino tambiên en justificar, a posterioni, los resultados de esos métodos. Dicho de otra manera: la tarea de la democracia es la creación de una experiencia más variada o de condiciones que favorezcan cambios continuos de medios que puedan dar lugar a nuevos fines y que permitan expresar las consecuencias de los que se enuncian en principios formales generales aceptados a través de su institucionalización.

Lo importante de esta idea, como he dicho, es que la democracia no se debe asociar con un conjunto especifico de fines. Rorty la usa muy a menudo cuando quiere extraer conclusiones éticas y políticas del modelo deweyano del crecimiento o desarrollo, o sea, de la idea de que «el proceso de crecimiento, de mejora y progreso, antes que el resultado estático, es lo que llega a resultar un asunto significativo» o que "el crecimiento mismo es el único fin "moral" ${ }^{28}$, pues es un fin que no demanda ningún tipo de conducta uniforme. Como dice Rorty, si se insiste y se pregunta al pragmatista: «icrecer para qué?», «iddesarrollarse con qué fin?», no podrá contestar otra cosa que: «para crear un futuro mejor». Y si se le pregunta «me- jor isegún qué criterio? », sôlo responderá: *"mejor en el sentido de que contiene más de 10 que consideramos bueno y menos de lo que creemos malo". Y cuando se le pregunta dy qué es lo que Ud. considera bueno?, sólo podrá contestar con Dewey: "crecimiento" $" 29$. Es cierto, como dice Rorty, que cuando Dewey hablaba así del crecimiento no tenía la intención de oponer esta actitud hacia la justificación de fines últimos a las teorías tradicionales del valor, pero también es importante darse cuenta de que el problema de fondo es qué tiene que ver la filosofía con esa apelación al crecimiento como único fin moral. Que la práctica de la filosofía no deba consistir por más tiempo en la búsqueda de léxicos con los que formular principios que aniadan a la acción un nivel de limitación más general que el ya establecido por la práctica no impide, por ejemplo, que aquélla pueda ayudar a mostrar la forma especifica en que la concepción de un sistema de principios, reglas o normas ha llegado a ser posible gracias a la creación de un contexto práctico en relación con el cual resulta inteligible. Como vamos a ver, ésta es la dirección que, contra la opinión de Rorty, Dewey quería darle a la filosofía.

\section{II}

Rorty sabe que Dewey se apoyó mucho en Jefferson para llegar a su defensa experimental de una democracia radical y, por eso, también ha querido interpretar el espíritu pragmático como una extensión de los propósitos que animaron al estatuto jeffersoniano sobre la libertad religiosa. Jefferson - dice Rorty - mostró que la posesión de virtudes sociales era el único requisito para la pertenencia a una comunidad política y que las creencias religiosas de cada ciudadano no cran necesarias para los fines públicos o de la justicia social, sino, como mucho, para la perfección pri- 
vada e individual. Rorty trata de extender esta actitud e intenta asociar la concepción pragmatista de la política como experimento con nuevos argumentos que muestren por qué hoy día el progreso moral en las comunidades democráticas, o su simple cxistencia, sigue siendo posible, y debe llevarse adelante, sin creencias filosóficas compartidas, sin otra aspiración común que la sola preservación de las libertades políticas. Por eso, frente a las concepciones sobre el bien común o frente a las teorias de la racionalidad comunicativa, Rorty cree que la frivolidad que, en relación con los temas filosóficos tradicionales, se derivaría del empirismo de Dewey (y la consecuente crítica a la filosofia con aspiraciones fundamentadoras) podría desempenar el mismo servicio que la frivolidad respecto a los temas religiosos y su separación de la política social: fortalecer cl compromiso moral que persiguen los ciudadanos de las democracias, esto es, la tolerancia y la solidaridad. Igual que el declinar de la fe religiosa no ha debilitado a las democracias liberales, sino que, según Rorty, las ha fortalecido, así el declinar de las creencias filosóficas podría representar un paso más allá en el enriquecimiento de la vida democrática ${ }^{30}$.

Lo polémico es que este argumento, que, como los de Dewey, quiere hundir sus raíces en el experimentalismo jeffersoniano, no sólo tiene como premisa la idea de que la filosofia se ha mostrado irrelevante o ineficaz en el terreno público, sino que ha podido obstaculizar los frutos que caracterizan al juego libre de las practicas y a la esperanza social y moral que se puede llegar a promover en las democracias con un consenso del sentido común. Esta confianza en el sentido común sigue teniendo su paralelo en Dewey, pero no así su conexión con un desarrollo social al margen de la filosofía. En efecto, dado que para Rorty las sociedades liberales no se han mantenido unidas gracias a crecn- cias filosóficas, es dilicil imaginar que la despolitización y reprivatización de la filosofía que él propone suscite mucho interés o produzca algún daño. Rorty trata de presentar su argumento como la expresión de la esperanza de que «el sentido común llevará a la gente a no ser [filosóficos], del mismo modo que en las democracias ricas un número creciente de habitantes han sido no teístas por sentido común ${ }^{31}$. Además, si como a él mismo le gusta decir, el pragmatismo debe entenderse como una antítesis del racionalismo de la llustración. aunque una antitesis que sólo fue posible, de forma dialéctica, en virtud de ese racionalismo ${ }^{32}$, el incremento de la frivolidad filosófica podría llegar a entenderse como un desarrollo dialéctico del propio supuesto ilustrado de que la religión, el mito y la tradición pueden contraponerse a la facultad de la Razón. Esto es lo que le pernite calificar de liberal su idea de que las instituciones democráticas no sólo deberian estár dirigidas a desvincular opiniones sobre la racionalidad, el yo, la naturaleza humana o el bien, del alcance de las leyes, o sea, no sólo deberían presevar la libertad de opinión, sino que «se propondrá separar esas discusiones de las que están centradas en la política social» ${ }^{33}$. Ésta, por así decirlo, cuida de sí misma, y cuando los filósofos admitan que la libertad y la justicia son las primeras virtudes comprenderán la facilidad con la que los pragmatistas se desentienden de la justificación de principios más generales ${ }^{34}$.

Rorty también se esfuerza por caracterizar como otro desarrollo pragmático de la Ilustración la tesis de que para una reflexión sobre la sociedad liberal son suficientes «el sentido común y la ciencia social», en las que - afirma- raramente aparecen teorías generales sobre el «yo" o la racionalidad ${ }^{35}$. Pero esta idea tiene un problema: es dudoso que el sentido común y las ciencias sociales ya estén libres en nuestras sociedades de ausos filosófi- 
cos» de nociones como «razón», «verdad», «yo» 0 «bien». La retórica pública que aún domina muchos de esos ámbitos no siempre está tan libre de nociones generales $y$, por tanto, resulta difícil creer que nuestras prácticas cotidianas y la ciencia normal no necesiten una acción dirigida hacia su propia reestructuración. En esta medida, la confianza en la autonomía del sentido común y las ciencias sociales parece en Rorty -a diferencia de Dewey-más una expresión de un deseo que consideración razonable del estado de las cosas. En cambio, Dewey pensó que la filosofía debía intervenir en la propia reestructuración de esos ámbitos, no apelando a una lógica general, sino, por cjemplo, describiendo históricamente las condiciones sociales y políticas que han permitido consolidar en esos ámbitos usos generalizadores de conceptos como «individuo», «sociedad» 0 «estado». En definitiva, aunque Dewey defendía la idea de una justificación autorregulada de las prácticas, también queria llevar adelante un modelo ilustrado de filosofía que pudiera contribuir a la reforma del sentido común y de las ciencias. La posición de Rorty, como vamos viendo, es bien diferente.

En Contingencia, ironia y solidaridad, Rorty intenta justificar el significado dc la concepción deweyana de la filosofía para una defensa postilustrada de la democracia liberal citando un texto de Reconstruction of Philosophy donde Dewey define la tarea de la filosofia futura como sclarificar las ideas de los hombres respecto a las contiendas sociales y morales de su propia época» ${ }^{36}$. Rorty elude cualquier compromiso con el uso que Dewey podía estar dando aquí al concepto de kclarificar»o a su relación con la tarea directiva que le atribuye en otros textos ${ }^{37}$; y más aún, elude un comentario del sentido educativo que llegó a tener para Dewey la filosofía práctica, esa descripción de las prácticas establecidas que están funcionando en un momento dado como paradigmas para la resolución de problemas. Pasa por alto, en definitiva, la conexión tan interna que Dewey veía entre la pragmatización de la filosofía y su uso social. Para él, «la filosotía está llamada a ser la teoría de la práctica con idcas lo suficientemente definidas como para que puedan operar en el ensayo experimental y asegurar la integración de la experiencia real», léase experiencia social; o que su uproblema central es la relación que existe entre las creencias acerca de la naturaleza de las cosas, que nos proporciona la ciencia natural, y las creencias acerca de los valores, aplicando este término a todo lo que suponemos dotado de una autoridad legitima para dirigir la conductas ${ }^{38}$.

Rorty tiene razón cuando recuerda que la actitud antiformalista de Dewey fue ambigua y que no acabó por empujarle a abandonar definitivamente la idea de una «ógica» general de la racionalidad ${ }^{39}$. Eso es cierto: Dewey no acaba de negar la necesidad de alguna lógica. Pero limitándose a llamar la atención sobre esa ambigüedad sin profundizar más sobre ella, Rorty evade uno de los problemas a cuya dilucidación Dewey creía que debía enfrentarse el pragmatismo: las dificultades para conciliar el ataque a una teoría filosófica general de la racionalidad y del bien con cl lema de que la filosofía del futuro podría estar llamada a ser la tcoría de la práctica. Es cierto que, para Dewey, los métodos y fines de la teoría de las prácticas pueden cambiar tanto como su objeto o contenido. Pero aunque Dewey admitiria que la teoría de las prácticas no puede alcanzar un método general y debe partir de una consideración de las variedades de solución que proporcionan las ciencias y el sentido común a problemas específicos, no renuncia a la idea de una filosofía empírica con intervención activa en la arena social.

En definitiva, y pese a Rorty, los problemas a los que se veía abocado Dewey 
eran, de hecho, muy semejantes a los que se tuvieron en la filosofía europea posthegeliana; por ejemplo, el problema de desarrollar ciencias culturales que no tralaran de asegurar otra cosa que las relaciones puramente inmanentes que guardan las formas de vida entre si y no la relación con un principio externo o con un sistema trascendente de fines. Los trabajos empíricos de Dewey en teoria de la educación y en psicologia social estaban, además, vertebrados por la idea de una naturalización del idealismo hegeliano del que le interesaba, entre otras cosas, el postulado de que las condiciones del conocimiento no podían consistir en algo que éste añadiera a la experiencia, sino, como mucho, en un «desarrollo autorregulado de la experiencia a través de la experiencia» ${ }^{40}$. Para él, «la auténtica importancia práctica del idealismo* era «que la filosofía ha sido la afirmación de la unidad de la razón y del mundo externo en idea o subjetivamente, aunque, si resulta ser así en idea debe, finalmente, asegurar las condiciones de su exprcsión objetiva» ${ }^{41}$, y creyó que asegurarse de la expresión objetiva de csa unidad pasaba necesariamente por el uso de instrumentos nuevos como los que propor. cionaban la tecnología y las ciencias contemporáneas, los medios de comunicación y el diseño de políticas reformistas radicales. Este uso de nuevas técnicas y medios por parte de la nueva filosofía social permitiría evitar algunos errores del idealismo, como desatender «el carácter específico y concreto de la situación de incertidumbre en que se produce el pensamiento»; desapercihir «la naturaleza empíricamente concreta de las materias, acciones e instrumentos con que se alcanzan la determinación y la coherencia y (...) convertir la unificacion, que es una tarea objetiva, real y experimental, limitada a situaciones concretas donde se la necesita, en un pensamiento universal que desemboca en un sucño que lo absorbe todo ${ }^{42}$. Por tanto, podríamos decir que lo que Rorty nunca ha querido entender es que los problemas de Dewey para justificar la tarea directiva de la filosofía práctica podian ser muy semejantes a los de la izquierda hegeliana o a los de la sociología del conocimiento, por poner dos cjemplos sólo en apariencia desemejantes. Pero, claro, eso romperia a ojos de Rorty el hechizo de la filosofía norteamericana como una tradición liberada de las obsesiones que han lastrado la tradición ilustrada europea ${ }^{43}$.

\section{III}

Por último, hay que insistir en que la diferente actitud que tienen Dewey y Rorty hacia la necesidad de la filosofía para la democracia tiene mucho que ver con ta posibilidad de que esta forma de vida, incluso comprendiendo sus fines experimentalmente, deba proporcionar alguna noción de bien común. En este punto Rorty ha simplificado la preocupación que tenía Dewey ante las dificultades de la democracia para crear lazos comunitarios en el marco de una política que para el pragmatismo no puede fundamentarse en principios generales, sino en la multiplicación de métodos particulares para la solución de problemas. Dewey no describió la democracia sólo como un experimento histórico. También afirmó que la democracia no era suna alternativa entre otros principios de la vida en asociación. Es la idea de la vida comunitaria propiamente dicha... Dondequiera que hay una actividad conjunta cuyas consecuencias son apreciadas como buenas por todas las personas individuales que participan en ella, y donde la realización del bien es tal que suscita el vigoroso deseo de un esfuerzo de mantenerlo precisamente porque es un bien comparido por todos, puede hablarse de una comunidad. La lúcida conciencia de una vida comunal, en todas sus impli- 
caciones, constituye la idea de la democracias ${ }^{44}$.

Para defender esta idea de la democracia como la forma de vida más recta para fomentar lazos comunitarios, Dewey también se apoyaba en el proyecto jeffersoniano de una organización política basada en pequeñas unidades locales autónomas lo bastante pequeñas como para que todos sus miembros pudieran tener comunicación directa y hacerse cargo de todos los asuntos de la comunidad. Aunque este proyecto nunca se llevó a cabo ni recibió mucha atención, Dewey creía que era la auténtica intención que había animado la actitud de Jefferson hacia la intromisión del poder gubernamental federal en la libertad y derechos de los Fstados. Precisamente hacia los años cuarenta Dewey presentia que, sin extremar la importancia de aquel plan, sí se podía cncontrar en él la indicación de un haz de problemas graves que afectaban al desarrollo de las democracias en ese momento, en concreto, los que envolvía el distanciamiento o asimetría entre el control individual de las consecuencias de los actos y el funcionamiento de los sistemas de producción. Para él, esa asimetría reclamaba la creación de asociaciones cara a cara "cuyas acciones recíprocas puedan compensar, si no controlar, la pavorosa impersonalidad de las avasalladoras fucrzas actuales» ${ }^{45}$. Las fuerzas económicas, añadía, whan ampliado inmensamente el campo de las actividades de asociación; pero lo han hecho en gran parte a expensas de la calidad intima y directa de los intereses y actividades del grupo comunal. El hábito norteamericano de "acoplarse" es un tributo a la realidad del problema, pero no ha hecho mucho por resolverlos ${ }^{46}$.

Está claro, por tanto, que los males que Dewey imputaba a la democracia liberal tenían que ver directamonte con la dislocación de intercambios de bienes comunitarios, pues sostenía que los vínculos vita- les sólo pueden crearse en la «intimidad de un intercambio que necesariamente es de alcance reducido»: «ठ̈Es posible cntonces - se preguntaba- restaurar la realidad de las organizaciones menos comunales y penetrar e impregnar a sus miembros con cl scntido de la vida en la comunidad local? (...) La democracia debe comenzar en casa y su casa es la comunidad vecinals ${ }^{47}$. En resumidas cuentas, la extensión del campo de asociación que había tenido, entre otros efectos, la eliminación de las distancias impedía a ojos de Dewey que los factores de asociación pudieran confinarse a las localidades $y$, justamente por eso, el problcma de un ajuste entre esas actividades extensivas y las actividades intensivas de intercambio comunal le pareció el problema «apremiante para la democracia». Ese ajuste, para decirlo más exactamente, «implica todavia mâs que el aprendizaje del proceso práctico de gobierno autónomo que Jefferson tenía presente» ${ }^{48}$. Implica, por ejemplo, el desarrollo de factores locales de comunicación y cooperación, la crcación de vinculos estables y leales que militen contra las fuerzas centrífugas de la cultura ky que al mismo tiempo sean de tal indole que respondan flexiblemente a las demandas de un público más numeroso, invisible $c$ indefinido. En grado muy considerable, los grupos que tienen una base funcional tendrán que reemplazar probablemente a los que se basan en la contigüidad física ${ }^{49}$.

En The Public and Its Problems Dewey aclara aún más la necesidad de rcimplantar vínculos comunales en el seno dc las relaciones funcionales que ha generado la democracia. No se trata de incoar en ésta alguna tradición concreta ni de fomentar el mantenimiento de comunidades aisladas donde las relaciones se vean favorecidas por la proximidad física. Más bien se trata de reformar las condiciones de una nueva esfera pública de participación que combine la extensión continua de su ámbito 
con la diferenciación local que evite su separación de la sociedad civil y su desarrollo meramente funcional. «A menos que la vida comunitaria local se reestablezca, lo público no podrá solventar adecuadamente sus problemas más urgentes; encontrarse e identificarse a si mismo. Pero si se reestablece, manifestará una plenitud, variedad y libertad en la posesión y disfrute de sentidos y bienes desconocidos en las asociaciones contiguas del pasado. Pues scrá viva y flexible, así como estable, y responderá a la escena complcja y mundial en que se ve imbuida. A la vez que local, no llegará a aislarse» ${ }^{50}$.

La actitud de Rorty frente a estas preocupaciones de Dewey ha sido, digámoslo directamente, simplificadora. En «Prioridad de la democracia sobre la filosofía» Rorty afirma que para Dewey el desencanto del ámbito comunitario en las democracias era un precio que se pagaba a gusto por la liberación privada individual que nos proporciona una esfera pública sustraída de nociones comunitarias sobre el bien. $O$ también, que Dewey consideró que no merecía la pena recuperar ninguno de los bienes conseguidos por las sociedades premodcrnas, si con ello disminuíamos la capacidad de una democracia para «dejar a la gente sola". Pero, como estamos viendo, la problemática de Dewey es harto más compleja. El problema no es si Dewey pensó que la noción política de la libertad individual sería suficiente para desentendernos de las nociones comunitarias sobre el bien que se hayan desarrollado en el pasado, sino, más bien, si la democracia, entendida en un sentido meramente procedimental, podia hacer de sus distintas comunidades algo más que un conjunto de grupos extraños entre sí. El problema para Dewey era, además, la clase de programas políticos y sociales que se debían llevar adelante para promover la expansión de una democracia multicultural, programas en los que, a su juicio, la filosofía social debía participar directamente, por ejemplo, a través de teorias educativas.

Llevaría más espacio del que dispongo analizar en detalle la creencia de Dewey de que la política debía ser una función de la teoría educativa ${ }^{51}$ y de otras ciencias sociales, pero lo que está claro es que, a su juicio, la imposibilidad del pragmatista para justificar por adelantado un fin inclusivo para la democracia no implicaba en sí misma ningún argumento a favor de la separación de filosofía y política. Rorty simplifica todo el problema de la relación entre pragmatismo, democracia y fines cuando dice que «el peligro de devolver al mundo su encanto consiste, desde un punto de vista deweyano, en el hecho de que ello podría interferir el desarrollo... de una "unión social de uniones sociales", uniones que podrían (según Fmerson, deberian) ser muy reducidas. $Y$ es que resulta muy dificil sentirse fascinados por una visión del mundo y ser tolerantes con todas las demás» ${ }^{52}$.

Como acabamos de ver, el problema de devolver el encanto al mundo no tiene que ver en la obra de Dewey con la recuperación nostálgica de lazos comunitarios tradicionales, pues la democracia ha creado unas condiciones en las que esta clase de vínculos contiguos ya no son eficaces. La democracia, sin embargo, ha proporcionado nuevos medios que permitirían la aparición de otros lazos comunitarios, ciertamente con un sentido distinto a los tradicionales, pero necesarios para asegurar, como diría Rorty, la solidaridad. Y Dewey ve precisamente en la filosofia social el medio para evitar la reducción de la politica a un método formal de decisión y de organización social que diluya los lazos comunitarios. A la filosofía social le correspondería, al menos, la identificación de lazos comunitarios nuevos a los que la política a menudo no puede atender o no quiere atender, proyectando nociones experimentales sobre las relaciones que podrian 
guardar entre sí distintos léxicos sobre el bien que pudieran coexistir en una democracia. Y también prescrvar al léxico de cada comunidad de su reducción a uno general, de carácter formal, con que el Estado-administrativo puede llegar a caracterizarlas. El problema de la filosofia es «definir los rasgos deseables de las formas de vida comunitaria que existen realmente, y utilizarlos para criticar los aspectos indeseables y sugerir mejoras». Respecto a un grupo social la filosofia investiga, por ejemplo, según Dewey, cuán numerosos y variados son los intereses conscientemente compartidos de cada una de esas formas de vida comunitaria, y cuán pleno y libre es el juego de acción y reacción con otras formas asociativas ${ }^{53}$. En última instancia, la función de la filosofía social consistía en la formación de opinión pública, lo cual implicaba, según Dewey, su compromiso en la difusión de los medios y valores de una forma de vida fuera de sus límites: aLa comunicación de los resultados de la investigación social es lo mismo que la formación de la opinión públicas ${ }^{54}$. En consecuencia, resulta difícil de creer que este modelo de la filosofía práctica sea compatible con la afirmación rortyana de la necesidad de relegar la filosofía fuera del ámbito público. Planteadas así las cosas, la tradición pragmatista parece estar muy lejos de haber sido siempre esa despreocupada alternativa norteamericana a la filosofía política europea que Rorty ha querido ver en ella.

\section{NOTAS}

1 Vease de R. Bernstein "Democracy: The Task Beforc Us", en Philosophical Profiles. Essays in a Pragmatic Mode, Philadelphia, University of Pennsylvania Press, 1986, pp. 260-273; también, «One Step Forward, Two Steps Backward: Rorty on Liberal Democracy and Philosophy" y aRorty's Liberal Utopias, en The New Consuliation, Cambridge, Mass., The MIT Press, 1992. De Thomas McCarthy: arilosofia y practica social el "nucvo pragmatismo" de Richatd Rorty" y, sobre todo, el final te sPostcriptum." Politica y arnbigütada, ambos en Ideales e llusiones (trad. de A. Rivero, Madrid, Tec. nos, 1992).

2 «Symposium on Consequences of Prapmatisms (R. Sleeper, Rorty's Pragnatisn: Aftort in Neurath's Boat, but Why Adrif?; A. Edel, A Missing Dimension. in Rorty's Lise of Pragmatism, y R. Rorty, Comments on Steeper and Edel), Transactions of the Peirce Society, XXI. 1985.

3 Véase, entre otros, W. Paringer, John Dewoy and the Paradax of Liberal Refom, Albany, State University of New York State, 1990; R. Westhrook, John Dewey and American Democracy, Ithaca, Comell University Press, 1991; T. Kautman-Osborne, Politic/SenselExperience: A Pragnatic Inquiry into the Promise of Democracy, Ithaca, Cornell University Press, 1991; J. Stuhr, John Dewey, Nashville, Carmichael and Charmichael, 1991, y «Dewey"s Reconstruction of Metaphysicsa, Transactions of the C. S. Peirce Society, vol. XXVIII, 1992, y J. Camphell, The Community Reconstructs: The Meaning of Pragmatic Socal Thought, Urbana, University of Illinois Press, 1992. Tambićn puede consultarse la cxcelente antología de trabajos criticos que ha cditado Jim Tiles, John Dewcy. Critical Assessments, Londres y Nucva York, Routledge, 1992; especialmente vols. II (Political Theory and Social Pracitce) y III (Vaiue, Conduct and Art). En castellano deben consultarse los siguientes trabajos: J. C. Geneyro, La democracia inquieta: E. Durkhein y J. Dewey, Barce. lona, Anthropos, 1991 (caps. IV y V), y M. Pía Lara, La democracia como proyecto de identidad ética, Barcelona, Antrophos, 1992 (espocialmente cap. VI).

* "Theory, Pragmatism and Politics", Consequences of Theon, Baltimore y Londres, The John IIopkins University Press, 1991, pp. 22-38; The Ameriran Fva. sion of Philosophy: A Genealogy of Pragmatism, Madison, Wisconsin, University of Winconsin Press, 1989. Sobre la relación entre Dewey, Rorty y West, véase el interesante trabajo de Angel Rivero «Liberalismo democracia y pragmatismo*, Isegoria. El nuevo prasmatismo, Madrid, CSIC-Instituto de Filosofia, 1993, pp. 49.64. Véanse también el análisis que R. Del Aguila hace de las contradicciones e implicaciones politicas del programa de Rorty en «El caballeso pragmático: Richard Rorty o el hibcralismo con rostro humanon, ibid., pp. $26-48$. 